\title{
Pichação + arte + educação: outros olhares
}

\begin{abstract}
Resumo
Neste artigo é abordado o conceito de pichação em experiências realizadas com adolescentes em uma escola pública de Santa Maria, RS. Ao entender a pichação a partir de características conceituais independentes dos preconceitos que a opõem ao grafite, ela pode dizer respeito às intervenções imprevistas que alteram o uso dado aos espaços, tirando o foco das verdades absolutas e se detendo em acontecimentos vividos. O objetivo dessa experiência foi problematizar as possibilidades de reinvenção dos lugares cotidianos, considerando as construções sociais que envolvem os sentidos dados a eles, o que resultou em ações, através da arte, onde os estudantes se envolveram em produções abertas às imprevisibilidades do contato com outras pessoas.
\end{abstract}

Palavras-chave: pichação; artes visuais; educação; reinvenção.

\section{Graffiti tagging + art + education: other views}

\begin{abstract}
This text approaches the use of the concept of tagging (graffiti) in experiences with teenagers from a public school in Santa Maria, RS. Tagging is here understood through conceptual characteristics which are independent to prejudices that oppose it to the graffiti. It may then relate to unforeseen interventions which alter the use we give to spaces, taking our focus out of absolute truths and detaining us on lived happenings. This research's objective was to discuss the possibilities of quotidian places' reinvention, pondering the social constructions which involve their given senses. That discussion results on actions, through art, where students involve themselves on productions which are open to the unpredictabilities of the contact with other people.
\end{abstract}

Keywords: graffiti tagging; visual arts; education; reinvention.

\section{Introdução}

\begin{abstract}
Toda arte que se preze tem de incomodar, causar no espectador algum tipo de reação à qual ele não está acostumado. A pichação é um bom exemplo de como cumprir bem este papel (WAINER, 2005, p.98).
\end{abstract}

Aceita ou não, a pichação se tornou um ato de intervir em algo já existente, de provocar impactos e reações em diferentes pessoas, de direcionar e alterar olhares para um fato ou lugar dentro da banalidade cotidiana, reinventando-a.

Como negar que tais características poderiam ser também, de um modo ou de outro, transferidas para aquilo que entendemos por arte e aquilo que pretendemos com a educação? Não é quando há incômodo, desajustes, como sugere Weiner (2005) no início deste texto, que discussões são levantadas e movimentadas para produzir nelas aprendizagens? 
Independente das implicações legais que pressupõe o ato de pichar $^{1}$, o que propus nessa pesquisa foi apropriar-me do conceito de pichação a partir de características que o construam para além de preconceitos diretamente ligados à ideia de ilegalidade e vandalismo. Entendo que a pichação pode se tornar vandalismo assim como pintar uma parede, tocar um instrumento no meio de uma praça ou colar um outdoor também o podem. Se o vandalismo está no ato de depredar um patrimônio público, aquilo que pode ou não ser considerado 'depredação' está no que é feito e alimentado socialmente para enquadrar algo dentro deste termo.

Neste artigo, descrevo algumas experiências vivenciadas no campo da educação no momento em que o tema pichação é tomado como foco de pesquisa junto a estudantes de uma escola de educação básica. Acreditando na possibilidade de reinvenção do uso do conceito 'pichação', de certo modo, já banalizado nos discursos acerca de espaços urbanos, investi em construções coletivas, onde os estudantes fossem capazes de criar seus próprios modos de ver e de criar algo.

Através da perspectiva da cultural visual (HERNÁNDEZ, 2011), desenvolvo uma pesquisa que indaga sobre as práticas culturais do olhar, bem como seus efeitos sobre quem vê e produz essas imagens. Assim, trata-se de uma pesquisa cujo posicionamento metodológico envolve pensar as imagens não por significados inerentes a elas, mas em considerar que tudo o que vemos é visto a partir de nós, e os sentidos que damos a certas imagens compõem aquilo que elas passam a ser para nós. A cultura visual aparece, então, como uma referência para situar os debates sobre o que vemos a partir das formas culturais e históricas que movimentam as visualidades (HERNÁNDEZ, 2011).

Não se trata de escolher um tema para suscitar comentários em sala de aula, coletando ou formando opiniões acerca dele, mas que esse tema seja ponto inicial para o atravessamentos de outras relações. Acredito que em uma educação onde os conceitos abordados não sejam fórmulas para ser decoradas, mas ingredientes para o devir, são abertos caminhos para fazermos de nossas vidas, modos de criação. Convém lembrar que o conceito de criação é apontado aqui a partir de Nietzsche (1999), o qual faz uso desse termo para falar de uma vida vivida enquanto processo de criação, ou seja, de uma postura de criação que não deseja verdades intrínsecas à realidade, mas que se abre a contínuas mudança, criando e desfazendo mundos como se os próprios acontecimentos do mundo fossem matéria de criação, sempre inacabados.

Nessa pesquisa, busquei fazer uso do conceito 'pichação' como disparador para traçar outras linhas acerca de experiências de mundo, entendendo que um objeto não traz significados inerentes a si, mas sentidos inventados socialmente e, portanto, passíveis de

\footnotetext{
${ }^{1}$ No Brasil, a pichação é tomada como o extremo oposto do grafite, inclusive através do artigo 65 da lei dos crimes ambientais 9605/98, sancionada no ano de 2011, pela presidente Dilma Rousseff, legalizando o grafite em detrimento da pichação.
} 
reinvenção. Desse modo, o objetivo dessa experiência foi problematizar, junto aos estudantes, as possibilidades de reinvenção dos lugares cotidianos habitados, considerando que os mesmos são construções sociais em constantes transformações, tendo suas existências movimentadas pela maneira como nos posicionamos frente às pseudo-certezas que nos são oferecidas.

\section{De onde partimos para falar de pichação?}

No senso comum, quando ouvimos qualquer definição sobre pichação a vemos associada ao conceito de grafite. É como se a pichação fosse o que há de ruim no grafite, a sua sobra. Vemos isso nos discursos urbanísticos, onde prefeituras defendem uma política de 'limpeza' das cidades, investindo em uma 'caça às bruxas' que preza por eliminar o que entendem como pichação ao mesmo tempo em que investir no embelezamento através do grafite.

A pichação é definida, na maioria das vezes, como uma condenável atitude de vandalismo, uma sujeira nas ruas da cidade, alimentando o preconceito de associar pichadores com gangues perigosas. De acordo com Gitahy (1999, p.19) alguns dos significados de pichação podem ser: "ação ou efeito de pichar; escrever em muros e paredes; aplicar piche em; sujar com piche; falar mal - de acordo com esse último conceito, não há quem não tenha pichado uma vez na vida".

A meu ver, classificar manifestações urbanas dentro de conceitos predefinidos é limitar suas potencialidades expressivas. Essas certezas, ao mesmo tempo em que geram tranqüilidade para quem as define, impõem dicotomias de bem versus mal que expressam generalizações simplistas tomadas como única verdade. Opto aqui, por falar da pichação, sem para isso contrapô-la ao grafite. Na realidade, não me deterei a falar sobre a pichação que há nas ruas, sobre aquela que todos conhecem, recriminando ou defendendo, mas de uma pichação a ser inventada, que é parte da vida de cada um. Pois ninguém vive sem pichar algo no mundo, sem reinventar as lisas paredes construídas antes da nossa passagem.

Opto por ver a pichação como um poder de resistência. E, sendo assim, por que não trabalhar a pichação na escola? Afinal, o que seria da educação se não nos dispuséssemos a produzir algumas pichações, algumas perturbações para com elas subvertermos algumas normalizações que nos imobilizam? 


\section{De dicotomias a multiplicidades visuais}

$\mathrm{Na}$ época em que vivemos, os enquadramentos legitimadores das metanarrativas, produtoras de verdades históricas, vão aos poucos sendo colocados em dúvida. Isso porque, segundo Veiga-Neto (2000), "as verdades são inseparáveis das políticas que as instituíram" (p.47). Isso não significa que as grandes narrativas estejam sendo substituídas, excluídas para a inserção de outras, mas que são produzidas desconfianças sobre elas, ao passo que são problematizados os lugares políticos de onde se originam, revelando o caráter contingente de seus enunciados. Não se trata de julgar as metanarrativas como mentiras que impedem o sujeito de compreender o mundo como ele 'realmente é', mas de reconhecê-las como verdades legitimadoras que descrevem uma possibilidade de mundo a partir de determinadas seleções, enquanto outras verdades podem estar sendo produzidas simultaneamente.

Toda prática social tem seu caráter discursivo imerso em invenções humanas, fazendo mais visível aquele que narra do que o próprio objeto narrado. As constantes discussões sobre as diferenças entre grafite e pichação nos fazem entender mais sobre a sociedade que narra, suas limitações lingüísticas e representativas do que sobre a arte de rua em si. O que faz com que algo esteticamente belo, figurativo e obediente à lei seja considerado arte ao passo que algo mais para o âmbito do protesto, com uma elaboração formal mais difícil de ser traduzida seja por isso considerado sujeira e vandalismo?

Não caberia avaliarmos o quanto uma representação é mais ou menos fiel àquilo que descreve, mas os modos como essa descrição constrói o próprio objeto descrito, idealizado. Com isso, Veiga-Neto aponta para os discursos enquanto práticas que formam os objetos e "não como um conjunto de palavras que representariam as coisas do mundo" (VEIGA-NETO, 2000, p.46). O grafite e a pichação são tratados, em muitas situações, como lados opostos de um determinado tipo de manifestação porque há discursos que assim os descrevem.

Para Schultz (2010, p.6), o sujeito educado, civilizado e universal, somente subsiste diante de sua negativa, o desajustado, perverso e intolerável. Essa contraposição entre civilizado e incivilizado vem acompanhada das figuras morais do sujeito "bom" e "mau".

Ao se referir aos conceitos criados de pichação e arte, Schultz acredita que essas iniciativas de classificação não dão conta dos movimentos que acontecem, ao passo que fixam e dicotomizam corpos no mundo.

Muitas vezes adentramos em uma cultura na expectativa de captar suas características a partir daquilo que a torna diferente daquela que assumimos como normalidade. Tratamos, assim, a diferença como a produção de oposições, fazendo um objeto diferente do outro por sua negatividade. Em outro sentido, a chamada différance, de Derrida, trata de efeitos de diferenças que não podem ser essencializadas, mas entendidas a partir de relações. Segundo Hall (2003, p. 60), différance "não se trata da forma binária de diferença entre o que é 
absolutamente o mesmo e o que é absolutamente 'Outro'. É uma 'onda' de similaridades e diferenças, que recusa a divisão em oposições binárias fixas."

Os lugares, assim como as culturas alimentadas dentro de seus instituídos limites, não possuem identidades definitivamente concluídas, não podendo ser descritos sempre como os mesmos, ao passo que se delineiam por narrativas que não são auto-suficientes, sendo envolvidos por processos globais sem que por isso se resumam a cópias de algum sistema colonizador.

Uma reportagem publicada no Diário de Fotógrafo (blog vinculado ao jornal Diário de Santa Maria), em fevereiro de 2012, mostra o quanto o posicionamento acerca da aceitação da pichação tem gerado discussões e controvérsias. Na matéria, o autor denuncia o desrespeito de pichadores com moradores de uma rua da cidade, classificando-os como 'vândalos'. Muitos dos leitores da postagem, no entanto, discordaram de seu posicionamento, notando contradição entre a crítica feita e as belas paisagens registradas pelas fotografias, argumentando que muitas das pichações presentes ali são sintomas dos problemas urbanos, a exemplo da precária educação e do alto custo do transporte público. Outros defenderam que o ato de pichar sem autorização deveria ser condenado, alegando diferentes motivos: uns por considerarem o resultado desagradável, outros pelo fato de ser executado em lugar indevido. Outra opinião vinha no sentido de sugerir que pichadores fossem instruídos para converterem-se a grafiteiros, ao mesmo tempo em que algumas pessoas defenderam a pichação enquanto arte.

$\mathrm{Na}$ semana seguinte, uma nova publicação no Diário do Fotógrafo (PIMENTEL, 2012a) buscou contornar as críticas anteriores através da divulgação de fotografias que registravam imagens de intervenções em outras ruas da cidade, dessa vez dando-Ihes o nome de grafite, porém sem deixar de afirmar o quanto estes se diferiam das imagens criticadas anteriormente.

Se fôssemos classificar tais manifestações pelo caráter invasivo de umas e harmonioso de outras, todas, de alguma forma, seriam pichação. A diferença está naquilo que aceitamos porque nos agrada e naquilo que condenamos por não encontrarmos critérios confortáveis para avaliar.

Gitahy (1999) fala de um conceito intermediário entre grafite e pichação que recebeu o nome de 'grapicho'. O 'grapicho', segundo ele, combina a escrita típica da pichação com um colorido mais elaborado e preocupado com a composição. Os limites visuais entre um e outro acabam se baseando em gostos pessoais, sendo que a lei que proíbe a pichação parece, no mínimo, desnecessária ao passo que a violação do patrimônio público continua resultando em penalidade independente de ser chamada por alguém de arte ou não, salvo alguns casos de artistas que obtiveram consagração (como Banksy e OsGemeos), fazendo com que as intervenções que produziram ilegalmente nas ruas obtivessem um elevado reconhecimento dentro do sistema das artes. 


\section{Pichação na escola: rabiscando brechas}

Se a pichação é algo que está mais para a transgressão, para o desvio aos padrões, o que seria a pichação dentro do espaço escolar?

Basta entrar em uma escola para percebermos o quanto marcas pessoais são deixadas pelos jovens, registrando sua passagem por ela. As marcas, seja por meios intencionais ou pelo desgaste do uso, demonstram o quanto esses espaços são habitados, o quanto há vida pulsante neles.

Maurício Villaça, um dos precursores da arte do graffiti no Brasil, partilhava da ideia de que graffiti são também as garatujas que fazemos desde a mais tenra idade, os rabiscos e gravações feitos em bancos de praça, banheiros, e até mesmo aqueles que surgem quando falamos ao telefone. Assim, também o graffitar que se difunde de forma intensa nos centros urbanos significa riscar, documentar, de forma consciente ou não, fatos e situações ao longo do tempo. Diz respeito a uma necessidade humana como dançar, falar, dormir, comer, etc. (GITAHY, 1999, p.1213).

Em 2010, teve início, na Universidade Federal de Santa Maria, um projeto de docência em Artes Visuais, desenvolvido junto ao PIBID (Programa Institucional de Bolsas de Iniciação à Docência), onde foram realizados projetos em duas escolas públicas da cidade a partir do tema 'arte pública'. Projetado para a execução durante as aulas de artes em turmas de ensino fundamental e médio, surgiu, posteriormente, a possibilidade de ministrar uma oficina em uma das escolas, ainda sobre o mesmo tema, mas funcionando em horário oposto ao turno estudado e estando aberta à participação de estudantes de turmas diversas. Minha participação enquanto bolsista neste projeto se deu tanto em salas de aula, quanto em uma oficina, mas me detenho, neste artigo, a destacar experiências dadas ao longo da oficina, na qual o tema 'pichação' se fez de modo mais intenso.

A oficina, que teve um público itinerante, entre 3 e 7 participantes por semana, permitiu ao projeto uma flexibilidade interessante, ultrapassando diversas barreiras comuns ao território escolar como: a da seriação, a do tempo rigidamente determinado, a do professor como figura central na sala de aula, a da sala de aula como sede de operações. Participavam estudantes da $8^{a}$ série ao $3^{\circ}$ ano do ensino médio, todos adolescentes com uma faixa etária entre 14 e 17 anos, além das crianças que, vez por outra, passavam e paravam para contribuir, sendo que a oficina se estendeu, algumas vezes, por quase quatro horas. A cada semana nos reuníamos no espaço que melhor atendesse às nossas necessidades: um dia no saguão, outro na sala de vídeo, algumas vezes no pátio e em outras circulando pelo espaço da escola.

Usando um termo discutido por Martins e Tourinho (2005), o que desenvolvemos neste projeto foi uma espécie de "currículo nômade", um ensino que não se instala numa 
única posição ou tendência teórica, vendo os sujeitos em trânsito, sem identidades fixas e ousando inventar seus próprios trânsitos (MARTINS E TOURINHO, 2005, p.105).

Tendo como ponto de partida o tema 'arte pública', não sabia ao certo aonde isso iria me levar, mas logo nos primeiros encontros, nosso 'currículo nômade' foi nos apontando caminhos e sendo construído: junto ao grupo de estudantes da oficina, surge o interesse em trabalhar sobre grafite urbano.

Em conversa com um dos participantes, no segundo encontro, vi que ele preenchia uma folha inteira com desenhos e signos, com uma destreza de quem não fazia isso apenas esporadicamente. Perguntei se ele era grafiteiro e a resposta foi, 'sou pichador'. Pichador... Não sei se essa resposta era uma provocação ou apenas um retorno sincero, mas certamente foi um incentivo para que repensasse meu planejamento.

Alguns encontros depois, após abordar algumas possibilidades de intervenções urbanas, coloquei em pauta o tema pichação, buscando, para além de preconceitos, dialogar com os estudantes sobre suas características (repetição, transgressão, questionamento, assinatura...).

Falar de pichação não deixou de causar certa desconfiança por pessoas que aprenderam a sempre separar tão claramente a 'bondade' do grafite da 'maldade' da pichação, mas busquei tratar esse conceito como modo de expressão, independente de seus pressupostos morais. Na escola era visível a presença de estudantes considerados pichadores, apesar de apenas um menino ter se encorajado a assumir-se como tal. Em vários momentos ouvi murmurinhos que planejavam ações noturnas e, em certo dia, um deles me confessou que planejavam entrar em uma ruína abandonada do centro da cidade para pichar.

Entre eles havia também uma clara distinção entre grafite e pichação. A pichação parecia Ihes interessar mais. Pichar era fugir do sistema, não uma fuga no sentido de covardia, mas de produzir fendas. Do modo como nos dizem Deleuze e Parnet (1988), "fugir não é renunciar às ações, nada mais ativo que uma fuga. É o contrário do imaginário. É também fazer fugir, não necessariamente os outros, mas fazer alguma coisa fugir, fazer um sistema vazar como se fura um cano" (p.49). É a criação de uma nova terra dentro da própria terra.

Muitos pichadores não se sentem à vontade por ter suas ações marginalizadas, eles a consideram arte, apesar de não desejarem ter sua arte cooptada pelo sistema. Um exemplo disso foi citado pelo próprio menino do segundo encontro, o coletivo Subsolo Art, de Santa Maria, grupo de grafiteiros que produz para o sistema (quando se envolvem em projetos de grafites incentivados pela prefeitura) e também fora dele (quando individualmente realizam tags nas paredes da cidade), e que defende não ver diferença entre um e outro (SPRAY, 2011). 
Comecei a pensar que seria mais interessante trabalhar com o conceito de pichação na escola, como uma possibilidade de fuga à normalidade. Minha intenção não foi de incentivar os estudantes a praticarem pichação nas ruas, mas de problematizar aquilo que pode ser pichação em nossas produções, num sentido mais amplo, a partir das próprias características que identificamos nela. Compreendendo outras maneiras de estudar a arte, que não limitada aos discursos históricos, abordamos a pichação como narrativa discursiva, que, segundo Hernández (2011, p. 41), "tende a fixar posições que têm efeitos não só sobre como vemos ou escutamos ou praticamos as artes, mas também em como mitificamos seu papel e sua presença na história, contribuindo com isto, para exclusões, silêncios, formas de poder...".

Se tomarmos a pichação tal qual ela é representada historicamente, diremos que o que há de pichação nas escolas são as marcas de vandalismos em paredes, banheiros e classes, diremos que é aquilo que torna a escola mais feia e descuidada, sendo, assim, inapropriada para ser desenvolvida pedagogicamente no território escolar. Mas pichação também pode ser uma intervenção imprevista de um estudante na aula de um professor, deixando-o desconcertado; pode ser a descoberta de que uma mesa, em outra posição, se transforma em quadro-negro; pode ser o encontro de amigos em um corredor destinado ao deslocamento.

Hernández (2011) acredita que, levando em consideração o campo dos estudos da cultura visual, discutir a questão dos objetos pedagógicos caberia menos à educação que abordar as estratégias para nos relacionarmos com eles. Nesse sentido, a pergunta que talvez pudéssemos responder não seria se a pichação pode ser incluída no currículo escolar, mas de "como favorecer a mudança de posicionamento dos sujeitos de maneira que passassem a constituir-se de receptores ou leitores a visualizadores críticos" (HERNÁNDEZ, 2011 , p.38). Pensando a prática educativa como algo que permite ao estudante construir maneiras de ver a si e ao mundo, a pichação não é utilizada para fixar discursos, levando indivíduos a se subordinarem a ela, mas para desencadear interpretações que não dizem respeito apenas ao objeto, mas a um posicionamento sobre nossas relações com o mundo.

Pichação é aquilo que escapa, que quer ser visto, mas que não se pretende eterno. Sejam manifestações individualistas, românticas, coletivas ou revolucionárias, elas se integram à paisagem, falam a partir da paisagem, mas querem ser mais do que isso. Querem sempre estar à margem, porque assim serão notadas. Formalmente se destacam pela repetição, pela demarcação anônima de territórios. São imagens em devir (DELEUZE, 1987), que não se pretendem eternas nem verdadeiras, mas que são acontecimentos. Os pichadores podem ser um exemplo daquilo que Deleuze e Parnet (1988) defendem na produção de uma literatura menor, uma saída da verdade absoluta para a produção de devires anônimos: 


\begin{abstract}
Estamos sempre dependurados sobre o muro das significações dominantes, estamos sempre mergulhados no buraco de nossa subjetividade, o buraco negro de nosso 'Eu' que nos é mais caro do que tudo. Muro onde se inscrevem todas as determinações objetivas que nos fixam, nos enquadram, nos identificam e nos fazem reconhecer; buraco onde nos alojamos, com nossa consciência, nossos sentimentos, nossas paixões, nossos segredinhos por demais conhecidos, nossa vontade de torná-los conhecidos (1988, p.58-59).
\end{abstract}

Talvez seja por esse devir que muitos pichadores defendem suas manifestações como arte, não para enquadrá-las dentro de critérios acadêmicos, mas por acreditar que esses critérios não são únicos, que pode existir uma arte fora da 'Arte' maior. E mesmo havendo aqueles que inscrevem seus nomes por toda a cidade, eles sabem que dificilmente alcançarão, por isso, algum reconhecimento pessoal, eles o fazem justamente para não serem capturados pela normalidade, para escaparem do sistema sem sair de dentro dele.

A pesquisa de dissertação de Olegário (2011) trata de uma investigação sobre as escritas anônimas presentes nas escolas, deixadas como rastros de uma literatura menor. Em um trecho de seu diário de campo ela descreve suas desconstruções e hipóteses surgidas ao longo da pesquisa:

\begin{abstract}
aos poucos fui me dando conta de que as escritas anônimas dos(as) estudantes se cruzam com a verdade/poder/saber institucionalizado, através de assinaturas, ora legíveis, ora ilegíveis, que encontrei no decorrer das andanças pela escola. Estes traços vêm aos poucos se tornando um enigma para mim. Enigma porque inverte o que dantes eu tinha como verdade (p.56).
\end{abstract}

Ao longo do texto, Olegário (2011) fala de um constante impulso por descobrir os autores dessas assinaturas, de situar o 'eu' de cada escrita, ao mesmo tempo em que acreditava que a morte do autor era necessária para que houvesse fugas da universalização, das amarras da verdade, da vontade de identidade.

Para trabalhar com a ideia de pichação, busquei praticar, junto aos estudantes, esse desejo por um anonimato dado na coletividade, produzindo marcas, fendas, que não almejassem se tornarem eternas e que demarcassem espaços a partir de questões emergentes.

Assim, produzíamos nos espaços e a partir deles. Estávamos em todos os lugares e a falta de uma sala de aula sempre disponível para a realização da oficina fez com que percebêssemos nossos produtos, bem como nossas ações, intensamente relacionados com os espaços e o público. O que poderia parecer uma forma de dispersão era na verdade uma espécie de imersão nos espaços de trabalho.

Passamos a produzir aquilo que denominamos 'pichação-arte', intervenções em contextos e momentos inesperados pela rotina escolar. 


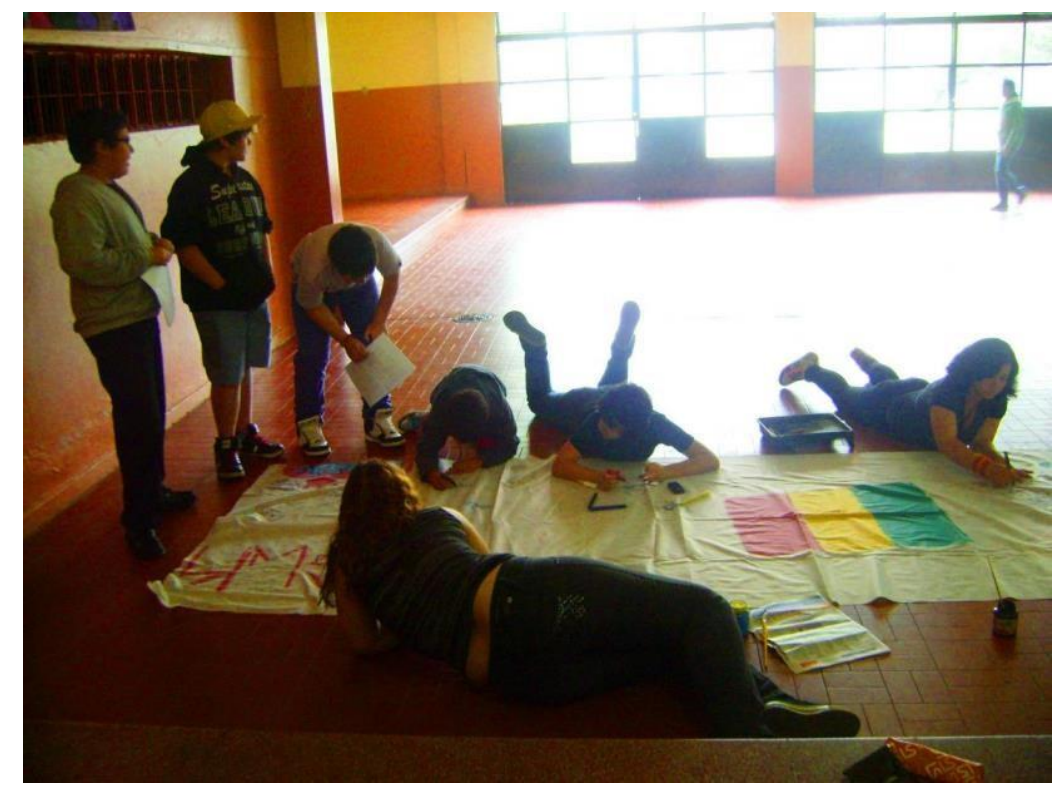

Figura.01: participantes da oficina trabalhando no saguão da escola Fonte: arquivo da pesquisadora

Durante a oficina construímos e desconstruímos o conceito de pichação. Houve uma sincronia de ideias onde todos sabiam e falavam de uma pichação que se construía conceitualmente. Por, na maioria das vezes, estarmos trabalhando em lugares de circulação de estudantes, havia sempre pessoas que não eram da oficina, mas que passando por onde estávamos, paravam e contribuíam, sendo que os adolescentes se habituaram a produzir de forma a permitir a participação de outras pessoas na composição dos trabalhos.

A exemplo disso, lembro de um encontro onde uma placa de compensado abandonada no pátio da escola foi recolhida pelos estudantes para ser transformada em uma cabana. Os estudantes participantes da oficina decidiram distribuir canetas para as crianças das séries menores, que se aglomeraram e disputaram espaço ao redor da placa para desenhar e escrever, mediados pelos adolescentes. A placa deixou de ser uma cabana e foi colocada no meio do pátio, tornando-se um 'monumento efêmero ao grafite'. Nesse dia o grupo decidiu chamar-se Grupo Pixarte. 


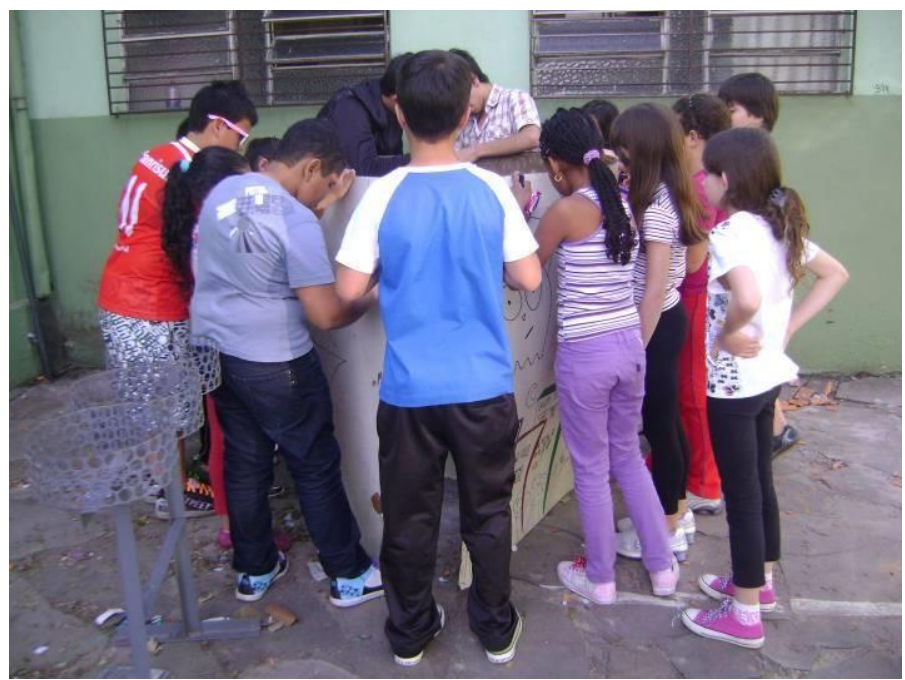

Figura.02: intervenção em placa de compensado Fonte: arquivo da pesquisadora

O trabalho coletivo gerava um anonimato que não os incomodava, pareciam estar mais interessados nas fugas, nas ações possíveis durante o encontro do que nas autorias de cada produção. Não era algo que exigisse uma nota mínima para que o trabalho não precisasse ser refeito e isso os deixava à vontade para não reivindicarem a autoria de tudo o que faziam.

A visualização de imagens de trabalhos como "Ossário"2, de Alexandre Órion, no qual o artista entra em um túnel de São Paulo e, limpando a fuligem acumulada, cria na parede um extenso mural de caveiras, desperta nos adolescentes a vontade de discutir sobre os conceitos e preconceitos que envolvem a arte de rua, percebendo possibilidades de praticar uma arte social, fazendo uso de materiais comuns na execução de uma arte que transgrida, que questione verdades antes inquestionáveis.

Obviamente, a oficina continuava submetida às limitações institucionais, no entanto, esses limites se tornavam agora mais difusos.

A duração de uma oficina, como descreve Corrêa (2006), a partir de suas próprias experiências em ensino não-formal, depende do interesse dos participantes. Essa oficina teve reduzido número de participantes, normalmente três por semana; foi intensa durante seus três meses de duração, mas acabou por se dissipar no final do ano. Findada num momento em que provas escolares e cursinhos pré-vestibulares tornaramse prioridade, onde a oficina, algo que nem avaliava, nem certificava, serviria como desvio para aquilo que se aprende na escola como de real importância: tornar-se um cidadão 'disciplinado' e 'qualificado' mediante inúmeros sacrifícios.

\begin{tabular}{ll}
\hline 2 & $\begin{array}{l}\text { Relatos sobre essa obra podem ser lidos no site do } \\
\text { artista: }\end{array}$ \\
http://www.alexandreorion.com/ossario/textos.html &
\end{tabular}




\section{Por um pouco mais de pichações na vida}

Acredito que nessas experiências a docência em devir possibilitou que produzíssemos fissuras em alguns preconceitos que colocavam a pichação como algo incondicionalmente ruim e impróprio ao espaço escolar, fazendo dessas problematizações possibilidades de criação.

Tais discussões, além de possibilitar que conhecessem diferentes pontos de vista sobre a pichação, tiraram os adolescentes, e também a mim, de uma zona de conforto que garantiria a certeza de ter um conteúdo apreendido dentro de uma concepção de certo e errado. Dispostos a inventar sentidos próprios para suas pichações, sem modelos seguros nos quais se basear, investiram em trabalhos coletivos que traziam mais perguntas do que respostas, que não visaram apresentar o resultado de suas façanhas nas aulas de arte, mas compartilhar problemas que mobilizavam suas vidas.

$\mathrm{Na}$ oficina, a rotina de estudantes de toda a escola pôde, por instantes, sofrer modificações, ao passo que professores, estudantes e funcionários se viram interpelados por inesperadas propostas de experiências artísticas nos corredores, das quais não só observavam, mas também participavam e contribuíam na construção. Sentiam o que Ihes afetava no instante atual, e produziam modos de vida. Saíam das obviedades, da brancura que cega, da tranquilidade que faz dormir.

Mais do que tornar acessíveis artefatos culturais, essa experiência se mostrou um investimento em uma educação para a resistência, para a invenção.

Desse modo, quando cada um desses estudantes sentir suas vidas pichadas por situações que formam e transformam suas aparentes identidades, lembrarão que eles podem pichar também, decidindo o que fazer com cada uma dessas interferências: apagando algumas, reproduzindo outras, transformando quando necessário e reinventando sempre.

\section{Referências}

CORRÊA, Guilherme Carlos. Educação, Comunicação, Anarquia: procedências da sociedade de controle no Brasil. Cortez Editora: São Paulo, 2006.

DELEUZE, Gilles. Nietzsche e a Filosofia. Lisboa: Ed.70, 1987.

DELEUZE, Gilles; PARNET, Claire. Diálogos. São Paulo: Escuta, 1988. 184p.

GITAHY, Celso. O que é graffiti. São Paulo: Brasiliense, 1999. (Coleção Primeiros Passos).

HALL, Stuart. Da Diáspora: identidade e mediações culturais. Belo Horizonte: Ed. UFMG, 2003. Parte I. A questão multicultural. pp.51-100 
HERNÁNDEZ, Fernando. A cultura visual como um convite à deslocalização do olhar e ao reposicionamento do sujeito. In MARTINS, Raimundo; TOURINHO, Irene. Educação da Cultura Visual: conceitos e contextos. Santa Maria: Ed. UFSM, 2011. pp. 31-49.

NIETZSCHE, Friedrich. Obras Incompletas. Editora Nova Cultura: São Paulo, 1999. OLEGÁRIO, Fabiane. Rastros das Linhas menores de escrita. Santa Cruz do Sul: Universidade de Santa Cruz do Sul, 2011 (Mestrado em Educação).

PIMENTEL, Jean. A Vez do Grafite. In Diário de Fotógrafo. Disponível em http://wp.clicrbs.com.br/diariodefotografo/?topo $=52,1,1,165, \mathrm{e} 165$. Acesso em 24 de fevereiro de 2012.

. Rua da Pichação. In Diário de Fotógrafo. Disponível em http://wp.clicrbs.com.br/diariodefotografo/?topo $=52,1,1,165, \mathrm{e} 165$. Acesso em 16 de fevereiro de 2012.

SCHULTZ, Valdemar. Pichação e Grafite: reverberações educacionais. In Anais da $33^{3}$ Anped. Caxambu, MG: 17 a 20 de outubro de 2010. Disponível em http://www.anped.org.br/33encontro/app/webroot/files/file/Trabalhos\%20em\%20PDF/GT2 4-6075--Int.pdf Acesso em 20 de fevereiro de 2012.

SPRAY: uma cultura viva em Santa Maria. Disponível em http://subsoloart.com/blog/2011/06/graffiti-spray-uma-cultura-viva-em-santa-maria-rs/. Acesso em 18 de fevereiro de 2012.

MARTINS, Raimundo; TOURINHO, Irene. Entre contingências e experiências vividas... Propostas para pensar um ensino crítico de artes visuais. In Visualidades. Revista do Programa de Mestrado em Cultura Visual/Faculdade De Artes Visuais/UFG Vol.3, No1, Jan-Jun/2005. Goiânia: FAV/UFG, 2005, pp. 87-111.

VEIGA-NETO, Alfredo. Michel Foucault e os Estudos Culturais. In COSTA, Marisa V. (Org.). Estudos Culturais em Educação: mídia, arquitetura, brinquedo, biologia, literatura, cinema. Porto Alegre: Ed. Universidade/UFRGS, 2000. pp. 37-72

WAINER, João. Pichação é arte. Super Interessante, São Paulo, n. 213, p.98, abril/maio 2005.

Tamiris Vaz (UFSM)

Recebido em: 30/10/2012

Aprovado em: $14 / 01 / 2013$ 